\title{
Young's Modulus of Austenite and Martensite Phases in Superelastic NiTi Wires
}

\author{
Petr Šittner, Ludek Heller, Jan Pilch, Caroline Curfs, Thiery Alonso, and Denis Favier
}

\begin{abstract}
Young's moduli of superelastic NiTi wires in austenite and stress-induced martensite states were evaluated by three different experimental methods (tensile tests, in situ synchrotron x-ray diffraction, and dynamic mechanical analysis) and estimated via theoretical calculation from elastic constants. The unusually low value of the Young's modulus of the martensite phase appearing in material property tables $(<40 \mathrm{GPa})$ is generally ascribed in the literature to the fact that stress-driven martensitic transformation and/or twinning processes continue even beyond the transformation range and effectively decrease the value of the tangent modulus evaluated from macroscopic stress-strain curve. In this work, we claim that this low value is real in the sense that it corresponds to the appropriate combination of elastic constants of the B19' martensite phase forming the polycrystalline wire. However, the Young's modulus of the martensite phase is low only for wire loaded in tension, not for compression or other deformation modes. It is shown that the low value of the martensite Young's modulus in tension is due to the combination of the unique coincidence of elastic anisotropy of the B19' martensite characterized by the low elastic constant $\mathrm{C55}$, austenite drawing texture, and strong martensite texture due to the martensite variant selection under tensile stress.
\end{abstract}

Keywords mechanical, modeling and simulation, non-ferrous metals

\section{Introduction}

Recoverable strains of SMA alloys generally consist of elastic, transformation, and thermal expansion strains. For general understanding and modeling the SMA functional responses as well as for the development of SMA devices, it is essential to mutually separate and evaluate these strains. Since in superelastic technologies focused at SMST we are dealing with recoverable strains of polycrystalline NiTi elements at constant temperature, thermal expansion is neglected here. However, distinction between elastic and transformation strains of NiTi polycrystal is already complicated, since it relies upon the knowledge of the elastic moduli of the austenite and martensite phases which is not trivial. Material property tables specify "elastic properties of NiTi" separately for austenite and martensite using relatively wide ranges, e.g., (Ref 1) as 41-75 GPa for the Young's modulus of the B2 austenite and 28-41 GPa for that of the B19' martensite. Such uncertainty is hardly acceptable for engineers designing superelastic NiTi devices, and it is suspicious that Young's modulus of martensite is

This article is an invited paper selected from presentations at the International Conference on Shape Memory and Superelastic Technologies 2013, held May 20-24, 2013, in Prague, Czech Republic, and has been expanded from the original presentation.

Petr Šittner, Ludek Heller, and Jan Pilch, Institute of Physics, ASCR, Prague, Czech Republic. Caroline Curfs, ESRF, Grenoble, France; and Thiery Alonso and Denis Favier, Université de Grenoble, Grenoble, France. Contact e-mail: sittner@fzu.cz. lower than that of the austenite. On top of that, elastic moduli of both phases vary strongly with temperature (Ref 2$)$, and martensite moduli may depend on the history; particularly, they can be different in tension and compression. So, there are some good reasons for the intervals appearing in material property tables.

In fact, the uncertainty in elastic moduli of NiTi originates mainly from (i) experimental difficulties associated with reliable determination of elastic constants, and (ii) temperature and history dependence of the effective Young's modulus of the wire associated with the martensitic transformation. Besides that, however, there is one more extremely important issue. In contrast to conventional materials, stress-induced phase transformations and/or twinning processes in SMAs create internal interfaces which are highly responsive to external stress. These interfaces may exist in the microstructure even at temperatures and macroscopic stresses far from the equilibrium transformation condition (far from the equilibrium transformation line in stress-temperature space). These mobile interfaces make it difficult to evaluate elastic properties of NiTi by conventional means from macroscopic stress-strain curves.

Elastic constants of austenite and martensite phases in SMAs can be beneficially measured on single crystals without applying external macroscopic stress by ultrasonic methods, particularly by resonant ultrasound spectroscopy (Ref 3, 4). However, since it is difficult to prepare NiTi martensite single crystal in a quality sufficient for the acoustic measurement, there are no reliable experimental data for elastic constants of the $\mathrm{B} 19^{\prime}$ martensite in the literature yet.

Given the lack of knowledge of elastic constants of the B19' martensite, theoreticians recently attempted to calculate them from the first principles (Ref 5-7). All the available results seem to suggest that martensite shall be the elastically harder phase, which clearly contradicts the overwhelming experimental evidence from tensile tests in the literature showing that Young's modulus of superelastic NiTi wire stretched beyond 
the transformation plateau into stress-induced martensite (Fig. 1a) is lower than in the austenite phase prior the plateau. The low martensite modulus of NiTi has been a longstanding puzzle in the SMA field. Hence, we decided to look at it more closely in this work.

\section{Experiments}

Medical grade superelastic NiTi wire provided by Fort Wayne Metals, NiTi \#1, straight annealed, $d=0.1 \mathrm{~mm}$, was used in present experiments. Young's moduli of the austenite and stress-induced martensite in these wires were evaluated by three experimental methods (tensile tests, in situ synchrotron $\mathrm{x}$-ray diffraction, and dynamic mechanical analysis). Figure 1a shows superelastic stress-strain curve of this wire stretched in tension till fracture, yielding values of the static Young's moduli $E_{\mathrm{A}}=66.8 \mathrm{GPa}$ (austenite) and $E_{\mathrm{M}}=24.8 \mathrm{GPa}$ (martensite). Electrical resistivity of the wire measured during the tensile test is superimposed. Note that the electrical resistivity increases with increasing stress both prior and after the plateau. It should stay constant, if there was elastic deformation only. It is known (Ref 8,9$)$ that, prior the plateau, this is due to the deformation processes related with R-phase and due to twinning and transformation after the plateau. So, it is obvious that evaluation
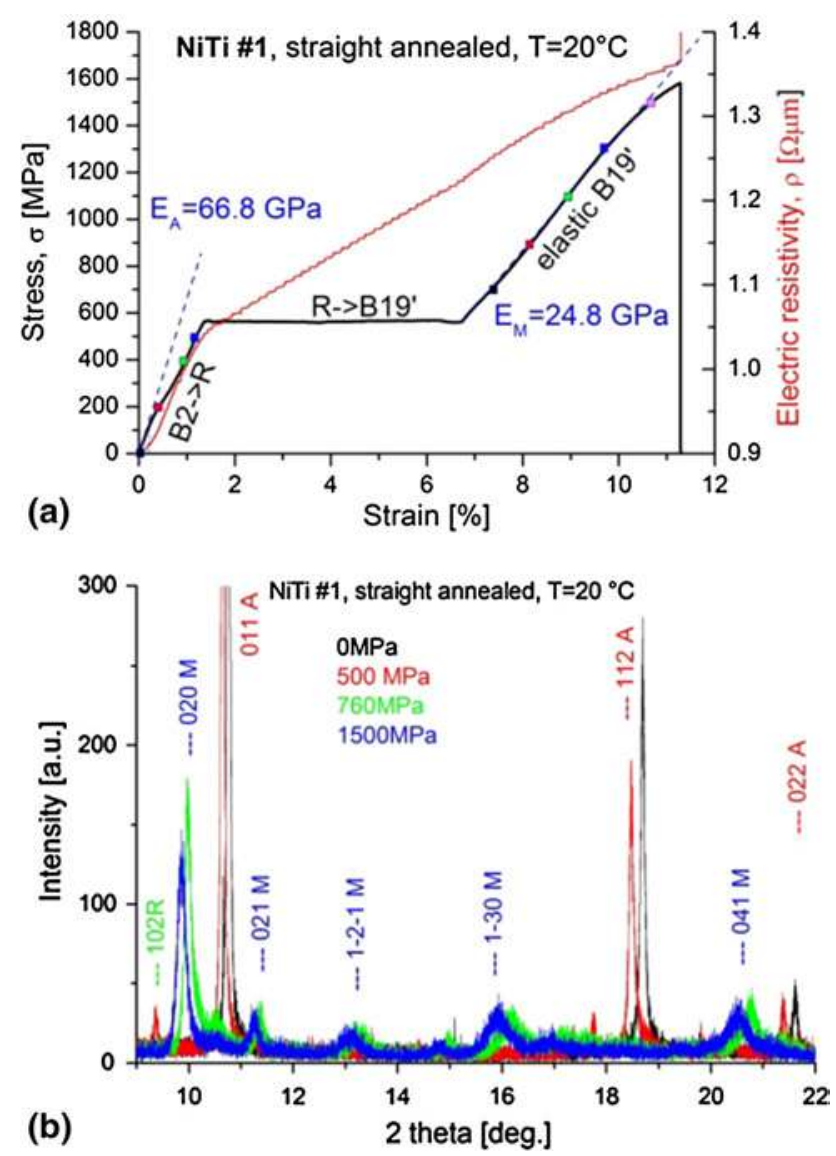

Fig. 1 a) Tensile $\sigma-\varepsilon$ curve of superelastic NiTi wire (FWM \#1, $d=0.1 \mathrm{~mm})$ at room temperature. Electrical resistivity of the wire measured during the tensile test is superimposed. (b) In situ x-ray diffraction patterns evaluated under applied tensile stress (denoted by points on $\sigma-\varepsilon$ curve in (a) in axial geometry (diffracting planes perpendicular to wire axis) of the Young's moduli from macroscopic responses in tensile tests on NiTi wires is thus highly questionable.

An alternative way which can be used for evaluating the elastic responses of solids regardless of the activity of other deformation processes in the studied sample is the in situ X-ray (neutron) diffraction method (Ref 10). In these methods, lattice strain $\varepsilon_{\mathrm{hkl}}$ is evaluated (Eq. 1) from the relative changes of the lattice spacing $d_{\mathrm{hkl}}$ (position of the hkl diffraction peak in the diffraction pattern) with increasing applied stress $\sigma . d_{0, \mathrm{hkl}}$ is the lattice spacing in stress-free state.

$\left.\varepsilon_{\mathrm{hkl}}=\left(d_{\mathrm{hkl}}-d_{0, \mathrm{hkl}}\right) / d_{0, \mathrm{hkl}}\right)$

To evaluate the strain component along the wire (load) axis, the diffracting lattice planes must be oriented perpendicularly to the load axis. Obviously, the strains $\varepsilon_{\mathrm{hkl}}$ evaluated from the changes of lattice spacings (shift of diffraction peaks) are elastic strains only. Since the intensity of the diffraction peak originates from a set of equally oriented grains of a particular phase within the gage volume of the polycrystalline wire, the lattice strains are oriented and phase-sensitive values that are averaged over the gage volume. If the values of lattice strains for various reflections are plot against the applied stress $\sigma$, the slopes of these dependences (Eq. 2) yield so-called diffraction elastic moduli, $D_{\mathrm{hkl}}$, characterizing the elastic properties of the material. If the material is not too much elastically anisotropic, then the slopes $D_{\mathrm{hkl}}$ for individual reflections are similar each other and their average value approaches the Young's modulus of the polycrystal.

$D_{\mathrm{hkl}}=\sigma / \varepsilon_{\mathrm{hkl}}$

The in situ synchrotron x-ray experiments in this work were performed using miniature deformation rig (Ref 11) installed on high-resolution powder diffractometer ID31 at ESRF Grenoble. The results for austenite and stress-induced martensite existing in the thin NiTi wire under applied tensile stress are given in Fig. 2 and 1 , respectively. The average value of austenite diffraction moduli $D_{\mathrm{A}}=70 \mathrm{GPa}$ is not that far from the value of Young's modulus measured in the stress-strain test. The stress-strain curves in Fig. 2a and $1 \mathrm{a}$ are different, since the NiTi wire was additionally annealed (Fig. 2a) to avoid the R-phase $(18 \mathrm{~ms} / 125 \mathrm{~W}$ treatment in Ref 11) complicating the analysis of the diffraction measurements prior the stress plateau. Applying the same method to the evaluation of elastic response of martensite is, however, a bit more complicated, since it is not straightforward to measure the stressfree lattice spacings $d_{0, \mathrm{hkl}}$ (martensite does not exist without stress at room temperature). On the other hand, we can measure more lattice strain-stress dependences (Fig. 3), since there is more martensite peaks in the martensite diffraction patterns (Fig. 1b). $d_{0, \mathrm{hkl}}$ for each martensite reflection was found by extrapolating the linear lattice strain-stress dependences to zero stress. The results clearly show that the orientation-dependent diffraction elastic moduli $D_{\text {hkl }}$ of the martensite are systematically higher $\left(D_{\mathrm{M}} \sim 120\right.$ $\mathrm{GPa}$ ), and the martensite phase is more elastically anisotropic than the austenite. The results thus contradict the low value of the martensite modulus evaluated from the tensile test.

Third method used to evaluate elastic properties of the NiTi wire was dynamic mechanical analysis. Theoretically, the dynamic modulus $E^{\prime}$ evaluated by this method from small amplitude vibrations superimposed over the macroscopic static stress-strain should not be affected by the activity of other deformation mechanism acting in the wire. Although this is the case for plasticity, it is not true for deformation processes derived from the martensitic transformation which are accompanied by 

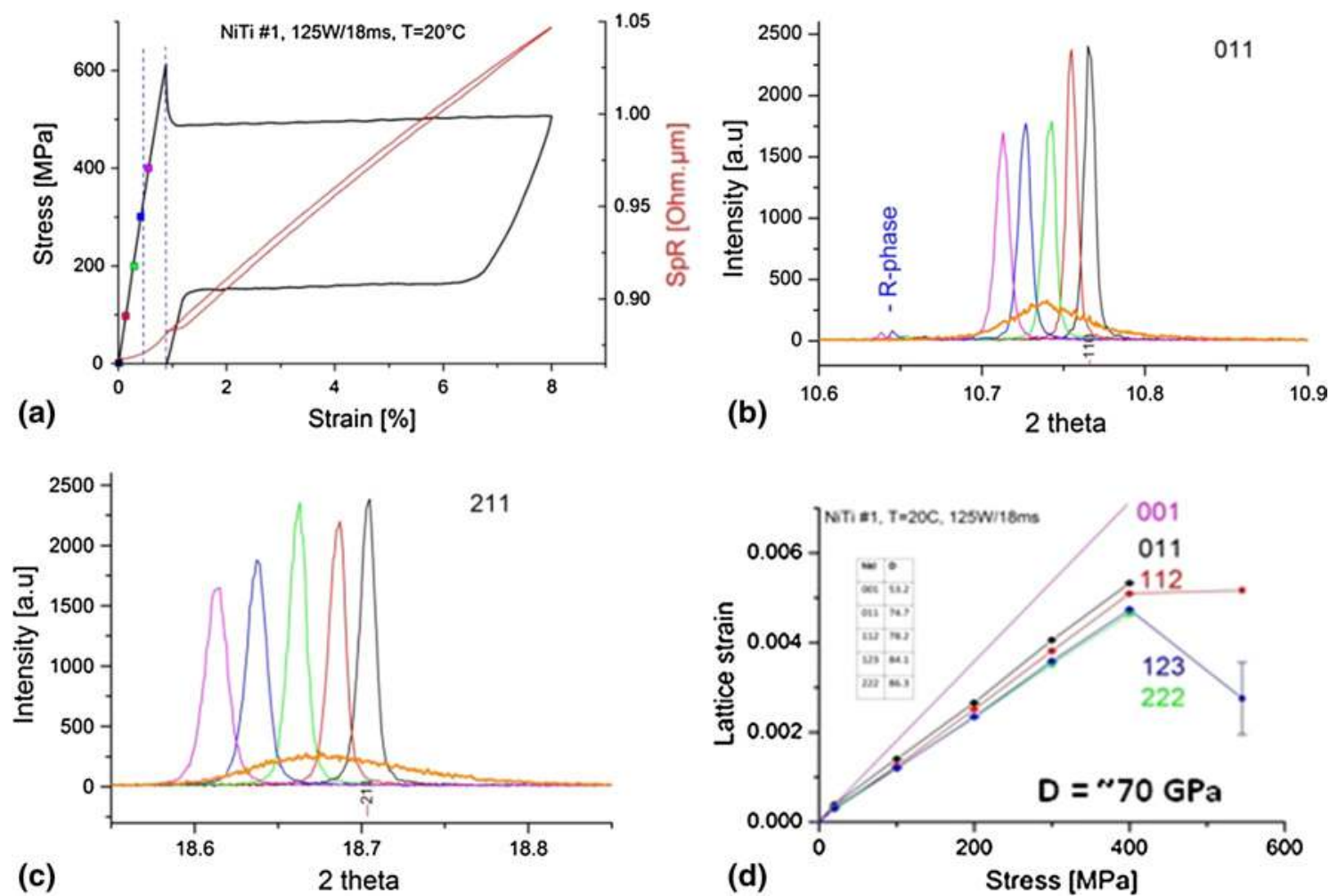

Fig. 2 Elasticity of the austenite evaluated from x-ray diffraction experiment on the high-resolution diffractometer ID31 at ESRF Grenoble, (a) tensile $\sigma-\varepsilon$ curve of the same NiTi wire additionally heat treated to avoid R-phase, Electrical resistivity of the wire measured during the tensile test is superimposed, $(b, c)$ peak shifts measured in the diffraction experiment at tensile stresses denoted on the $\sigma-\varepsilon$ curve in (a). Broad yellow profiles were obtained after unloading after full superelastic cycle, (d) lattice strain-stress diagram showing linear "lattice plane responses" of various austenite hkl reflections (Color figure online)

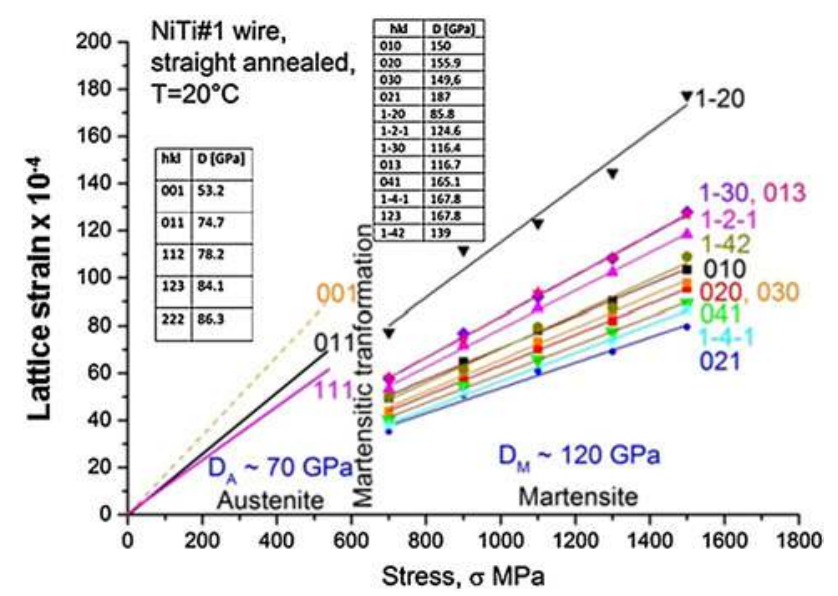

Fig. 3 Elasticity of martensite evaluated from the x-ray diffraction experiment on the high-resolution diffractometer ID31 at ESRF Grenoble. Diffraction elastic moduli $D_{\mathrm{hkl}}$ of austenite and martensite appearing as slopes of the lattice strain-stress dependence (measurement points in Fig. 1a beyond the plateu)

the phase change or lattice orientation changes giving rise to the mobile internal interfaces. Figure 4 shows the evolution of $E^{\prime}$ during a superelastic test on NiTi wire at room temperature till fracture (Fig. 4a) and during cyclic superelastic test at $T=37{ }^{\circ} \mathrm{C}$ (Fig. 4b). Note that, prior the start of martensitic transformation, the dynamic elastic modulus $E^{\prime}$ increases with stress at lower temperature $T=19^{\circ} \mathrm{C}$, while at higher temperature $T=37^{\circ} \mathrm{C}$, it decreases. This is the effect of the R-phase. The change of the $E^{\prime}$ with the applied stress during stress-induced B2-R transformation has a form of U-shape. We see only the second branch of the $U$ at lower temperature $T=19{ }^{\circ} \mathrm{C}$ (Fig. 4a), while only the first branch of it at $T=37^{\circ} \mathrm{C}$ (Fig. 4b). If there is no R-phase, $E^{\prime}$ stays constant during the elastic loading of the austenite (Fig. 2a). This method can be used in principle to evaluate the elastic properties $\left(E^{\prime}\right)$ of the NiTi wire also in case of phase mixtures (1-7\% strain) within the transformation range, see the hysteretic variation of $E^{\prime}$ in Fig. $4 \mathrm{~b}$. The variation of $E^{\prime}$ with strain is not U-shaped but linear due to the propagation of localized deformation in shear bands. The most important information to be inferred from Fig. 4, however, is that, although the dynamic elastic modulus $E^{\prime}$ of martensite increases with increasing stress beyond the plateau, it never exceeds a maximum value of $E^{\prime} \sim 50 \mathrm{GPa}$ (Fig. 4a). The $E^{\prime}$ increases upon stressing the wire beyond the transformation plateau since the twinning and transformation processes continue beyond the plateau but their activity gradually expires. The maximum of the $E^{\prime} \sim 50 \mathrm{GPa}$ observed at $10 \%$ strain corresponds to their complete expiration not due to the onset of the plasticity.

\section{Theoretical Calculations}

In order to understand the apparently inconsistent experimental results presented above, we tried to estimate Young's moduli of the B2 austenite phase and stress-induced monoclinic B19' martensite phase in NiTi wire by theoretical calculations. The idea is rather simple. First, we calculated single crystal 

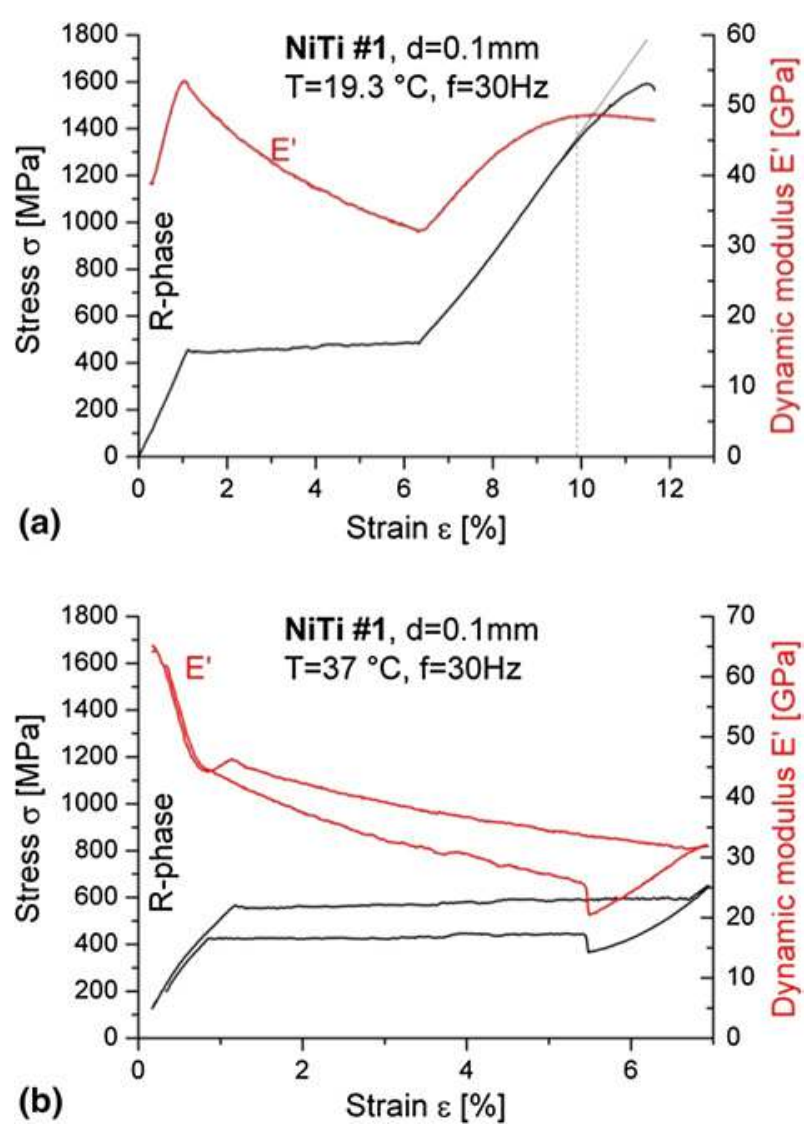

Fig. 4 Tensile $\sigma-\varepsilon$ curves of superelastic NiTi wire (NiTi \#1, $d=0$, $1 \mathrm{~mm}$ ) with superimposed dynamic modulus $E^{\prime}$ evaluated in DMA experiment using frequency $f=30 \mathrm{~Hz}$ (a) at room temperature $T=19{ }^{\circ} \mathrm{C}$ till fracture and (b) cyclic test at ambient temperature $T=37{ }^{\circ} \mathrm{C}$

Young's modulus $E_{\mathrm{hkl}}$ along a given austenite crystal direction $\mathrm{hkl}_{\mathrm{A}}$, and check how it changes with the stress-induced martensitic transformation in tension/compression. Ideally, this would correspond to the slope of elastic response of austenite single crystal loaded in tension/compression along the hkl direction prior and after the stress-induced transformation. The single-crystal moduli were calculated based on the knowledge of (i) crystal lattice parameters and (ii) elastic constants of both austenite and martensite phases, (iii) lattice correspondence between austenite and martensite yielding information on how particular austenite crystal direction transforms into the product phase, and (iv) martensite variant selection rule telling which martensite variant will form by the application of uniaxial tensile and compressive strain along particular austenite crystal direction. Figures 7 and 8 inform the orientation and sense of loading dependence of the single-crystal moduli. Finally, the polycrystalline Young's moduli are estimated taking into account grain constraints and textures.

\subsection{Input Parameters}

Crystallographic lattice parameters of the B2 austenite and B19' martensite phases are listed in Table 1 including matrices used for transforming Miller indexes hkl into vectors in Cartesian system (xyz) aligned with lattice unit cells of austenite and martensite. Matrix operators, lattice correspondence, and related matrix operators are given in Table 2, and finally, elastic constants of the austenite and martensite phases taken from literature $(\operatorname{Ref} 5,12,13)$ are given in Table 3.

\subsection{Martensite Variant Selection Rule}

In order to evaluate how Young's modulus of the austenite single crystal will change with stress-induced martensitic transformation when loaded along a specific direction in tension/compression, one has to decide which one of the 12 martensite variants will form, i.e., one needs to adopt a martensite variant selection rule. This is already an approximation, since we implicitly assume here that the austenite single crystal will transform into a single martensite variant, which yields maximum transformation strain into the load axis direction and sense of loading (tension or compression).

In order to apply the above martensite variant selection rule, we calculated orientation dependence of transformation strains for all 12 martensite variants using transformation matrix $\mathbf{T}_{\mathrm{B} 2 \rightarrow \mathrm{B}^{\mathrm{x}} \mathbf{9}^{\prime}}$ relating crystal directions of $\mathrm{B} 2$ austenite $(\mathrm{uvw})^{\mathrm{T}}$ and $\mathrm{B} 19^{\prime}$ martensite (UVW) ${ }^{\mathrm{T}}$ in the Cartesian system aligned with B2 austenite unit cell (Eq. 3). In these calculations, lattice parameters with related operators (Table 1) and austenite/ martensite lattice correspondence with related operators (Table 2) are used.

$$
\begin{aligned}
& \left(\begin{array}{c}
\mathrm{U} \\
\mathrm{V} \\
\mathrm{W}
\end{array}\right)=\mathbf{T}_{\mathrm{B} 2 \mathrm{~B} 19^{\prime}}^{\mathrm{xyz}} \cdot\left(\begin{array}{c}
\mathbf{u} \\
\mathbf{v} \\
\mathbf{w}
\end{array}\right), \\
& \mathbf{T}_{\mathrm{B} 2 \rightarrow \mathrm{B} 19^{\prime}}^{\mathrm{xyz}}=\mathbf{R}_{\mathrm{B} 19^{\prime} \rightarrow \mathrm{B} 2} \cdot \mathbf{T}_{\mathrm{hk} 1 \rightarrow \mathrm{xyz}}^{\mathrm{B} 19^{\prime}} \cdot\left(\mathbf{T}_{\mathrm{hk} 1 \rightarrow \mathrm{xyz}}^{\mathrm{B} 2} \cdot \mathbf{T}_{\mathrm{B} 19^{\prime} \rightarrow \mathrm{B} 2}^{\mathrm{hk}}\right)^{-1} .
\end{aligned}
$$

Transformation strain related to individual martensite variant $i(i=1-12)$ is calculated using transformation stretch matrix $\mathrm{U}_{i}$ that is computed through polar decomposition of the transformation matrix $\mathbf{T}_{\mathrm{B} 2 \rightarrow \mathrm{B} 19^{\prime}}^{\mathrm{xyz}}$ defined for each variant. Then, engineering strain was used to calculate transformation strain tensor $\varepsilon_{i}$ i.e., $\varepsilon_{i}=1 / 2\left(\mathrm{U}_{i}^{\mathrm{T}}+\mathrm{U}_{i}\right)-I$, where $I$ stands for $3 \times 3$ identity matrix. Orientation dependence of tensile/compressive transformation strains was evaluated through projection of the transformation strain tensor to all orientations i.e., tensile/ compressive transformation strain for variant $i$ along direction $e=e^{\mathrm{T}} \varepsilon_{i} e$. The results for martensite variant 3 are shown in Fig. 5. Orientation dependence of the maximum transformation strain in compression (a) and tension (b) in a single quadrant of austenite coordinate system are shown in Fig. 6. Note that (i) transformations strains are statistically larger in tension than in compression, and (ii) while one martensite variant is sufficient to be considered within the basic stereographic triangle in tension, three martensitic variants need to be considered in compression.

\subsection{Calculation of Orientation-Dependent Single-Crystal Moduli}

From the above calculation, we know the load axis orientations within the martensite phase which corresponds to each austenite crystal direction and sense of loading. Based on this, we calculate orientation dependence of the single crystal Young's moduli using the elastic constants and show it in Table 3 (constants from Ref 5 were used). The results for martensite variant 3 yielding largest strains in tension are shown in Fig. 7, and for three martensite variants 1, 5, and 9 yielding larger transformation strains in compression in are shown in Fig. 8. Since plot of four surfaces in a single figure are difficult to inspect, sections along $\{011\}$ austenitic planes are shown. 


\begin{tabular}{|c|c|c|c|c|c|}
\hline & $\begin{array}{c}\text { Lattice } \\
\text { parameters }\end{array}$ & $\left(\begin{array}{c}u \\
v \\
w\end{array}\right)$ & $=\mathbf{T}_{\mathbf{h k l} \rightarrow}^{\mathbf{B 2} / \mathbf{B} 1}$ & $\underset{\rightarrow x y z}{{ }_{319}^{\prime}}$. & $\left(\begin{array}{l}\mathbf{h} \\
\mathbf{k} \\
\mathbf{l}\end{array}\right)$ \\
\hline B2 austenite & $a_{0}=0.3015 \mathrm{~nm}$ & $\mathbf{T}_{\mathrm{hkl} \rightarrow \mathrm{xyz}}^{\mathrm{B} 2}=$ & $\left(\begin{array}{cc}\mathbf{a}_{\mathbf{0}} & \mathbf{0} \\
\mathbf{0} & \mathbf{a}_{\mathbf{0}} \\
\mathbf{0} & \mathbf{0}\end{array}\right.$ & $\left.\begin{array}{c}\mathbf{0} \\
\mathbf{0} \\
\mathbf{a}_{0}\end{array}\right)$ & \\
\hline B19' martensite & $\begin{array}{l}a=0.2889 \mathrm{~nm} \\
b=0.4120 \mathrm{~nm} \\
c=0.4622 \mathrm{~nm} \\
\beta=96.8\end{array}$ & $\mathbf{T}_{\mathrm{hkl} \rightarrow \mathrm{xyz}}^{\mathrm{B} 19^{\prime}}=$ & $\left(\begin{array}{c}\mathbf{a} \\
\mathbf{0} \\
\mathbf{c} \cdot \cos (\beta)\end{array}\right.$ & $\begin{array}{l}\mathbf{0} \\
\text { b } \\
\mathbf{0}\end{array}$ & $\left.\begin{array}{c}\mathbf{0} \\
\mathbf{0} \\
\mathbf{c} \cdot \sin (\beta)\end{array}\right)$ \\
\hline
\end{tabular}

\subsection{Effect of Grain Interactions and Texture on Polycrystalline Young's Moduli}

The next step should be to calculate Young's modulus of polycrystalline wire. Since the wire is not a set of isolated crystals but a polycrystalline aggregate, in which the individual single crystal grains mutually interact when exposed to external loading, an averaging homogenization scheme must be adopted to calculate homogenized polycrystalline Young's modulus (Ref 14-16). Although this topic has been widely addressed in the literature, there are issues making it difficult to be applied to NiTi wires as follows: (i) the crystal orientations are not distributed randomly in the aggregate but some grain orientations prevail due to the strong texture of the thin wire (Fig. 9), (ii) it is not realistic that whole grain transforms into one of the 12 lattice correspondent variants in Table 2, and (iii) it is not realistic that the wire transforms fully to the martensite state under stress. Typical NiTi wire texture results in a preferential orientation of polycrystal grains along the $111_{A}$ direction as Fig. 9 shows. Although the latest averaging schemes published in the literature go much far beyond the Voigt and Reuss approximations allowing for taking into account the effects of texture (Ref 16), grain size distribution (Ref 15), and even multiphase microstructure (Ref 14) of the polycrystal, their application to NiTi polycrystal in martensite state is still problematic. There is one major critical issue-if we want to compare the theoretical and experimental results, we need to assure that the phase and twin interfaces do not move under the increasing applied stress. Since we are lacking reliable inputs for i-iii needed for homogenization and since the aim of this work was mainly to clarify the long-lasting puzzle of the low martensitic modulus of $\mathrm{NiTi}$ in material property tables, polycrystalline Young's moduli were not calculated but only estimated in this work.

\section{Discussion}

\subsection{Young's Modulus of the Wire in Austenite Phase}

The values of the Young's modulus of the polycrystalline austenite phase evaluated by all methods converge around $E=70 \mathrm{GPa}$. Theoretically calculated value of the homogenized polycrystal Young's modulus (Ref 14) with random grain orientation distribution is $E=78.57 \mathrm{GPa}$ for elastic constants (Ref 3 ) in Table 3 . If we consider the texture of NiTi drawn bars with preferential $111_{\mathrm{A}}$ directions along the load axis and cubic elastic anisotropy of the austenite (Fig. 7), then the polycrystalline Young modulus of the real wire in austenite will even slightly increase. On the other hand, the B2 austenite phase undergoes softening upon cooling prior the martensitic phase transformation. Based on the work (Ref 17), the elastic constant $\mathrm{C} 44$ decreases upon cooling from $40 \mathrm{GPa}$ at $600 \mathrm{~K}$ to $25 \mathrm{GPa}$ at $200 \mathrm{~K}$ and $C^{\prime}$ from 20 to $14 \mathrm{GPa}$. If we use the value of $\mathrm{C} 44=33 \mathrm{GPa}$, which can be read from Fig. 3 in Ref 17 in the calculation (Ref 14), then we obtain $E=70 \mathrm{GPa}$ $300 \mathrm{~K}$. So, it can be concluded that the experimentally measured Young's modulus of the polycrystalline austenite phase $E=70 \mathrm{GPa}$ agrees very well with the theoretical polycrystalline modulus calculated from the elastic constants, given the mentioned uncertainties.

On the other hand, it shall be mentioned that much smaller values of austenite modulus can be read from experimental stress-strain curves of superelastic NiTi wires measured in experiments and reported in the literature. It comes out from the present analysis that if a smaller value of austenite Young's modulus is measured in the supposedly elastic loading, then it is either due to the stress-induced B2-R-phase transformation, R-phase reorientation, and/or due to internal intergranular stresses and residual martensite introduced by cycling into the wire microstructure. The activity of the R-phase related processes can be hardly recognized from the shape of the stress-strain curve, since it can be almost linear. However, the activity of the R-phase related processes can be easily understood (Ref 8,9) from the results of in situ electric resistance (compare the electric resistance responses in Fig. 1a and $2 \mathrm{a}$ ) or from DMA experiments ( $E^{\prime}$ does not vary with stress in case of true elasticity). Any value of the NiTi austenite polycrystalline modulus lower than $E=70 \mathrm{GPa}$ measured in experiments is thus not real but connected to the experimental issues.

\subsection{Young's Modulus of the Wire in Martensite Phase}

Young's modulus of the stress-induced martensite evaluated from stress-strain curves in tensile tests on NiTi $\# 1$ is $E=25 \mathrm{GPa}$ (Fig. 1a). The dynamic modulus evaluated in 
Table 2 Lattice correspondence and related lattice correspondence matrices, and rotation matrices associated with the cubic B2 to monoclinic B19' martensitic transformation yielding 12 latticed correspondence variants)

\begin{tabular}{|c|c|c|c|c|c|}
\hline Variant & {$[100]_{m}$} & {$[010]_{m}$} & {$[001]_{m}$} & $\mathbf{T}_{\mathbf{B} 19^{\prime} \rightarrow \mathbf{B} 2}^{\mathbf{h k l}}$ & $\mathbf{R}_{\mathbf{B}^{1} 9^{\prime} \rightarrow \mathbf{B} 2}$ \\
\hline 1 & {$[100]_{a}$} & {$[011]_{a}$} & {$\left[\begin{array}{ll}0 & \overline{1} 1\end{array}\right]_{a}$} & $\left(\begin{array}{ccc}1 & 0 & 0 \\
0 & 1 & -1 \\
0 & 1 & 1\end{array}\right)$ & $\left(\begin{array}{ccc}1 & 0 & 0 \\
0 & \sqrt{2} / 2 & -\sqrt{2} / 2 \\
0 & \sqrt{2} / 2 & \sqrt{2} / 2\end{array}\right)$ \\
\hline 2 & {$[\overline{1} 00]_{a}$} & {$\left[\begin{array}{lll}0 & \overline{1} & \overline{1}\end{array}\right]_{a}$} & {$\left[\begin{array}{ll}0 & \overline{1} 1\end{array}\right]_{a}$} & $\left(\begin{array}{ccc}-1 & 0 & 0 \\
0 & -1 & -1 \\
0 & -1 & 1\end{array}\right)$ & $\left(\begin{array}{ccc}-1 & 0 & 0 \\
0 & -\sqrt{2} / 2 & -\sqrt{2} / 2 \\
0 & -\sqrt{2} / 2 & \sqrt{2} / 2\end{array}\right)$ \\
\hline 3 & {$[100]_{a}$} & {$\left[\begin{array}{ll}0 & \overline{1} 1\end{array}\right]_{a}$} & {$\left[\begin{array}{ll}0 & \overline{11}\end{array}\right]_{a}$} & $\left(\begin{array}{ccc}1 & 0 & 0 \\
0 & -1 & -1 \\
0 & 1 & -1\end{array}\right)$ & $\left(\begin{array}{ccc}1 & 0 & 0 \\
0 & -\sqrt{2} / 2 & -\sqrt{2} / 2 \\
0 & \sqrt{2} / 2 & -\sqrt{2} / 2\end{array}\right)$ \\
\hline 4 & {$[\overline{100}]_{a}$} & {$\left[\begin{array}{ll}01 & \overline{1}\end{array}\right]_{a}$} & {$\left[\begin{array}{lll}0 & \overline{1} & \overline{1}\end{array}\right]_{a}$} & $\left(\begin{array}{ccc}-1 & 0 & 0 \\
0 & 1 & -1 \\
0 & -1 & -1\end{array}\right)$ & $\left(\begin{array}{ccc}-1 & 0 & 0 \\
0 & \sqrt{2} / 2 & -\sqrt{2} / 2 \\
0 & -\sqrt{2} / 2 & -\sqrt{2} / 2\end{array}\right)$ \\
\hline 5 & {$[010]_{a}$} & {$[101]_{a}$} & {$\left[\begin{array}{ll}10 & \overline{1}\end{array}\right]_{a}$} & $\left(\begin{array}{ccc}0 & 1 & 1 \\
1 & 0 & 0 \\
0 & 1 & -1\end{array}\right)$ & $\left(\begin{array}{ccc}0 & \sqrt{2} / 2 & \sqrt{2} / 2 \\
1 & 0 & 0 \\
0 & \sqrt{2} / 2 & -\sqrt{2} / 2\end{array}\right)$ \\
\hline 6 & {$\left[\begin{array}{ll}0 & \overline{1} 0\end{array}\right]_{a}$} & {$\left[\begin{array}{lll}\overline{1} 0 & \overline{1}\end{array}\right]_{a}$} & {$\left[\begin{array}{ll}10 & \overline{1}\end{array}\right]_{a}$} & $\left(\begin{array}{ccc}0 & -1 & 1 \\
-1 & 0 & 0 \\
0 & -1 & -1\end{array}\right)$ & $\left(\begin{array}{ccc}0 & -\sqrt{2} / 2 & \sqrt{2} / 2 \\
1 & 0 & 0 \\
0 & -\sqrt{2} / 2 & -\sqrt{2} / 2\end{array}\right)$ \\
\hline 7 & {$[010]_{a}$} & {$\left[\begin{array}{ll}10 & \overline{1}\end{array}\right]_{a}$} & {$\left[\begin{array}{ll}\overline{1} 0 & \overline{1}\end{array}\right]_{a}$} & $\left(\begin{array}{ccc}0 & 1 & -1 \\
1 & 0 & 0 \\
0 & -1 & -1\end{array}\right)$ & $\left(\begin{array}{ccc}0 & \sqrt{2} / 2 & -\sqrt{2} / 2 \\
1 & 0 & 0 \\
0 & -\sqrt{2} / 2 & -\sqrt{2} / 2\end{array}\right)$ \\
\hline 8 & {$\left[\begin{array}{ll}0 & \overline{1} 0\end{array}\right]_{a}$} & {$[\overline{101}]_{a}$} & {$\left[\begin{array}{ll}\overline{10} & \overline{1}\end{array}\right]_{a}$} & $\left(\begin{array}{ccc}0 & -1 & -1 \\
-1 & 0 & 0 \\
0 & 1 & -1\end{array}\right)$ & $\left(\begin{array}{ccc}0 & -\sqrt{2} / 2 & -\sqrt{2} / 2 \\
-1 & 0 & 0 \\
0 & \sqrt{2} / 2 & -\sqrt{2} / 2\end{array}\right)$ \\
\hline 9 & {$[001]_{a}$} & {$[110]_{a}$} & {$[\overline{1} 10]_{a}$} & $\left(\begin{array}{ccc}0 & 1 & -1 \\
0 & 1 & 1 \\
1 & 0 & 0\end{array}\right)$ & $\left(\begin{array}{ccc}0 & \sqrt{2} / 2 & -\sqrt{2} / 2 \\
0 & \sqrt{2} / 2 & \sqrt{2} / 2 \\
1 & 0 & 0\end{array}\right)$ \\
\hline 10 & {$\left[\begin{array}{ll}00 & \overline{1}\end{array}\right]_{a}$} & {$\left[\begin{array}{ll}\overline{1} & \overline{1} 0\end{array}\right]_{a}$} & {$[\overline{1} 10]_{a}$} & $\left(\begin{array}{ccc}0 & -1 & -1 \\
0 & -1 & 1 \\
-1 & 0 & 0\end{array}\right)$ & $\left(\begin{array}{ccc}0 & -\sqrt{2} / 2 & -\sqrt{2} / 2 \\
0 & -\sqrt{2} / 2 & \sqrt{2} / 2 \\
-1 & 0 & 0\end{array}\right)$ \\
\hline 11 & {$[001]_{a}$} & {$[\overline{1} 10]_{a}$} & {$\left[\begin{array}{lll}\overline{1} & \overline{1} 0\end{array}\right]_{a}$} & $\left(\begin{array}{ccc}0 & -1 & -1 \\
0 & 1 & -1 \\
1 & 0 & 0\end{array}\right)$ & $\left(\begin{array}{ccc}0 & -\sqrt{2} / 2 & -\sqrt{2} / 2 \\
0 & \sqrt{2} / 2 & -\sqrt{2} / 2 \\
1 & 0 & 0\end{array}\right)$ \\
\hline 12 & {$\left[\begin{array}{ll}00 & \overline{1}\end{array}\right]_{a}$} & {$\left[\begin{array}{ll}1 & \overline{1} 0\end{array}\right]_{a}$} & {$\left[\begin{array}{ll}\overline{1} & \overline{1} 0\end{array}\right]_{a}$} & $\left(\begin{array}{ccc}0 & 1 & -1 \\
0 & -1 & -1 \\
-1 & 0 & 0\end{array}\right)$ & $\left(\begin{array}{ccc}0 & \sqrt{2} / 2 & -\sqrt{2} / 2 \\
0 & -\sqrt{2} / 2 & -\sqrt{2} / 2 \\
-1 & 0 & 0\end{array}\right)$ \\
\hline
\end{tabular}

DMA experiments increases from 30 to $50 \mathrm{GPa}$ (Fig. 4a). These values are indeed lower than the austenite modulus. The low value of martensite elastic modulus is generally ascribed in the literature to the fact that the wire microstructure is not completely martensitic at the end of the plateau and that the martensitic transformation and/or twinning processes continue to proceed beyond the transformation plateau in the linear quasielastic range. This is most likely the reason why the dynamic modulus $E^{\prime}$ from the DMA test increases from 30 to $50 \mathrm{GPa}$ (Fig. 4a). But why there is this maximum of $50 \mathrm{GPa}$ ? We have never found a higher value in DMA tests. That was a puzzle.

On the other hand, results of in situ x-ray diffraction experiments (Fig. 3) have shown significantly higher values of 
Table 3 Elastic constants of austenite and martensite phases calculated from the first principles in Ref 5-7

\begin{tabular}{|c|c|c|c|c|c|c|c|c|c|c|c|c|c|}
\hline Phase [Ref.] & $\begin{array}{c}\mathrm{C}_{11} \\
(\mathrm{GPa})\end{array}$ & $\begin{array}{c}\mathrm{C}_{12} \\
(\mathrm{GPa})\end{array}$ & $\begin{array}{c}\mathrm{C}_{13} \\
\text { (GPa) }\end{array}$ & $\begin{array}{c}\mathrm{C}_{15} \\
\text { (GPa) }\end{array}$ & $\begin{array}{c}\mathrm{C}_{22} \\
\text { (GPa) }\end{array}$ & $\begin{array}{c}\mathrm{C}_{23} \\
(\mathrm{GPa})\end{array}$ & $\begin{array}{c}\mathrm{C}_{25} \\
(\mathrm{GPa})\end{array}$ & $\begin{array}{c}\mathrm{C}_{33} \\
\text { (GPa) }\end{array}$ & $\begin{array}{c}\mathrm{C}_{35} \\
\text { (GPa) }\end{array}$ & $\begin{array}{c}\mathrm{C}_{44} \\
\text { (GPa) }\end{array}$ & $\begin{array}{c}\mathrm{C}_{45} \\
(\mathrm{GPa})\end{array}$ & $\begin{array}{c}\mathrm{C}_{55} \\
\text { (GPa) }\end{array}$ & $\begin{array}{c}\mathrm{C}_{66} \\
(\mathrm{GPa})\end{array}$ \\
\hline Austenite & 169 & 138 & $\ldots$ & $\ldots$ & $\ldots$ & $\ldots$ & $\ldots$ & $\ldots$ & $\ldots$ & 40 & $\ldots$ & $\ldots$ & $\ldots$ \\
\hline Martensite (Ref 5) & 223 & 129 & 99 & 27 & 241 & 125 & -9 & 200 & 4 & 76 & -4 & 21 & 77 \\
\hline Martensite (Ref 6) & 188 & 122 & 89 & 14 & 231 & 108 & -10 & 245 & 22 & 77 & -12 & 45 & 90 \\
\hline Martensite (Ref 7) & 249 & 129 & 107 & 15 & 245 & 125 & -3 & 212 & -1 & 87 & -4 & 66 & 86 \\
\hline
\end{tabular}

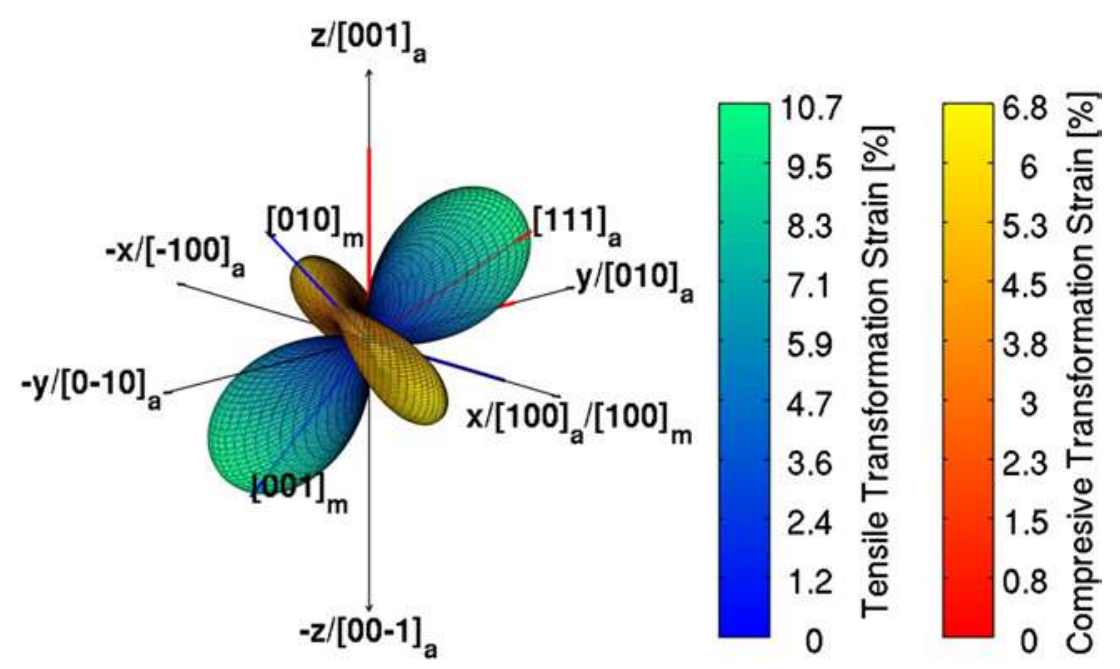

Fig. 5 Orientation dependence of tensile/compressive transformation strain for martensite variant 3 shown in coordinate system aligned with austenite cubic unit cell
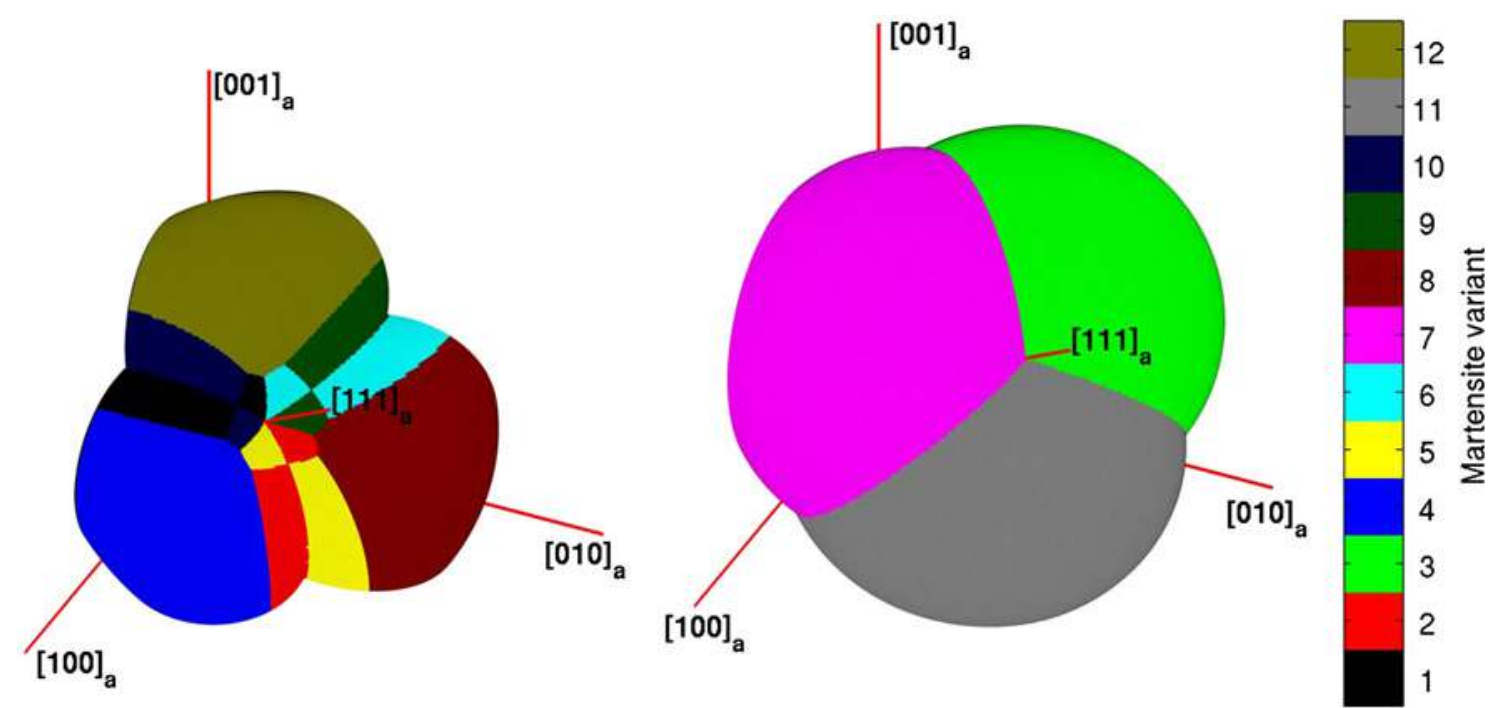

Fig. 6 Orientation dependence of the maximum transformation strain in compression (left) and in tension (right) with respect to activated martensite variants shown in coordinate system aligned with austenite cubic unit cell (one quadrant only)

diffraction elastic moduli for most of the studied reflections, frequently larger than $100 \mathrm{GPa}\left(D_{\mathrm{M}} \sim 120 \mathrm{GPa}\right)$. Let us note that the diffraction elastic moduli are neither single crystal nor polycrystalline Young's moduli, and they have to be calculated (Ref 10) by homogenization scheme similarly as polycrystalline Young's moduli. Stebner et al. (Ref 18) performed detailed confrontation of diffraction elastic constants of thermally induced B19' martensite with experimentally calculated ones from elastic constant from Ref 5, 7. They found better agreement for the set (Ref 5) than for the set (Ref 7), equally as we found for stress-induced martensite.

Looking closely on the diffraction elastic moduli in Fig. 3, we find that all the $D_{\mathrm{hkl}}$ are rather large, except of the $D_{1-20}$ which is much lower $(85 \mathrm{GPa})$. The diffraction peak $1-20_{M}$ 


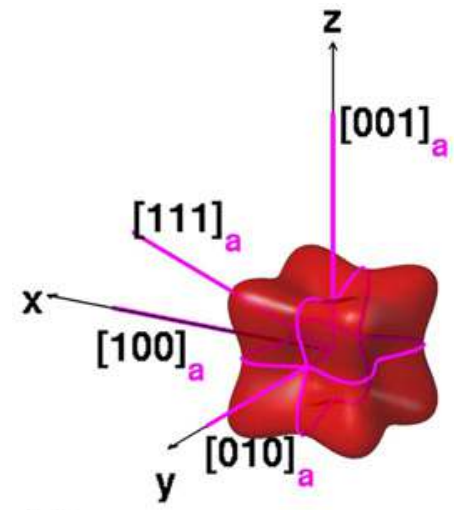

(a)

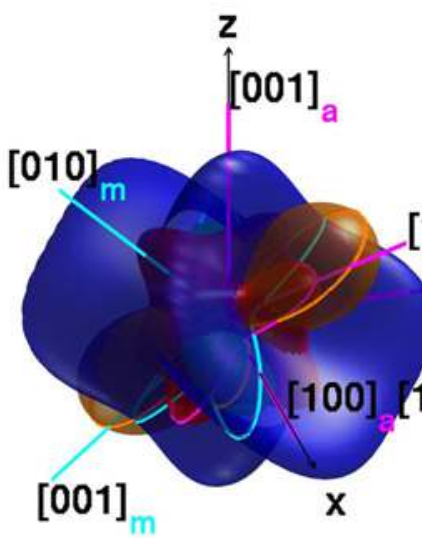

(c)

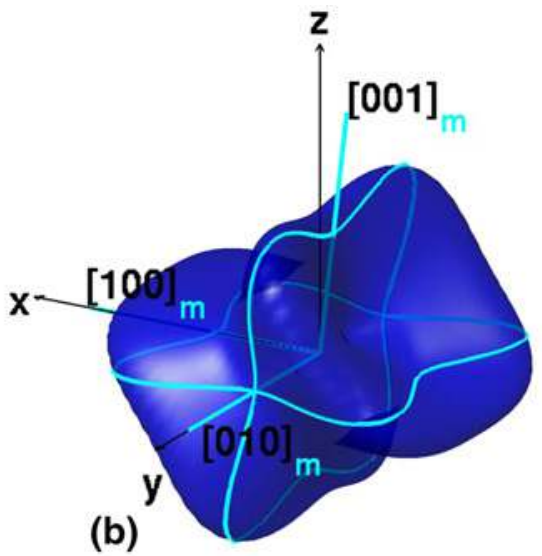

(b)

$[-100]]_{a} /[-100]$

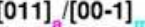

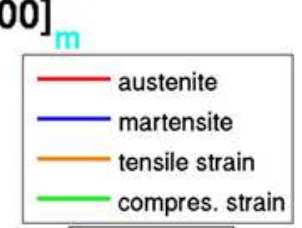

$(0-11) /(010)$

(d)

Fig. 7 Orientation dependence of Young's modulus (austenite in red and martensite in blue) and transformation strain (yellow in tension and green in compression) for austenite (a) and martensite variant 3 (b) which appears preferentially in tension. The orientation dependences are shown in a form equal value surfaces in space (a-c) and equal value contours (d) in cross section along the (0-11) $a$ plane. Young's moduli surfaces are plot together with transformation strain surfaces in $(c, d)$ to point out which directions are relevant for tension (Color figure online)

corresponds to $111_{\mathrm{A}}$ austenite reflection (although not observed in the $\mathrm{x}$-ray spectra, this is a very large diffraction peak in neutron diffraction spectra (Ref 19). Yet completely different values of diffraction elastic constants of martensite were obtained on thermally induced martensite in the by Rajagopalan et al (Ref 20). This made us to think about the elastic anisotropy of B19' martensite; and indeed, the orientation dependence of martensite single crystal Young's modulus (Fig. 7) shows a deep minimum in martensite direction $10-1_{M}$ aligned with $111_{\mathrm{A}}$ directions. In other words, that means that if the martensite variant 3 is stress induced from the austenite crystal by pulling it along $111_{\mathrm{A}}$ direction, then its single crystal Young's modulus will be as low as $33.2 \mathrm{GPa}$, which is the value in the minimum. In smaller extent, this is true for any load axis direction. Taking into account the very strong $111_{\mathrm{A}}$ fiber texture of the drawn wire, the puzzle was solved. Young's modulus of the wire in tensile stressinduced martensite is low due to the coincidence of the elastic anisotropies of the B2 and B19' phase, austenite drawing texture, and martensite variant selection under tensile stress.

The next question which immediately appeared was how is it in compression. Figure 8 shows Young's moduli surfaces for three variants 1, 5, and 9 producing largest transformation strains in compression. It can be seen that, along the directions of the large compression strain, the austenite surface is always located within the martensite surface. In other words, this means that, when the martensite crystal is created by compression along any austenite direction, the single crystal Young's modulus will always increase. This suggests that Young's modulus of the wire in compression stress-induced martensite should be higher than the austenite modulus. Confronting this conclusion with experimental results (Fig. 10), it seems to be true.

However, week point of this analysis is that the elastic constants of the B19' martensite in Table 3 are not measured experimentally but calculated theoretically from the first principles. The three sets of elastic constants in Table 3 are mutually different, and we do not know which one is the correct one. Moreover, it is likely that there is elastic softening of the martensite elastic constants occurring upon heating, and we do not know whether and which elastic constants soften. For comparison, see experimental evidence on $\mathrm{C}_{55}$ and $\mathrm{C}_{\mathrm{MS}}$ softening of the orthorhombic $2 \mathrm{H}$ martensite in $\mathrm{CuAlNi}$ upon heating reported in Ref 4 . Hence, we have calculated orientation dependence of austenite and martensite moduli for all three sets of elastic constants in Table 3 and plot them in Fig. 11b-d. Note that the austenite modulus surface (Fig. 11a), which 

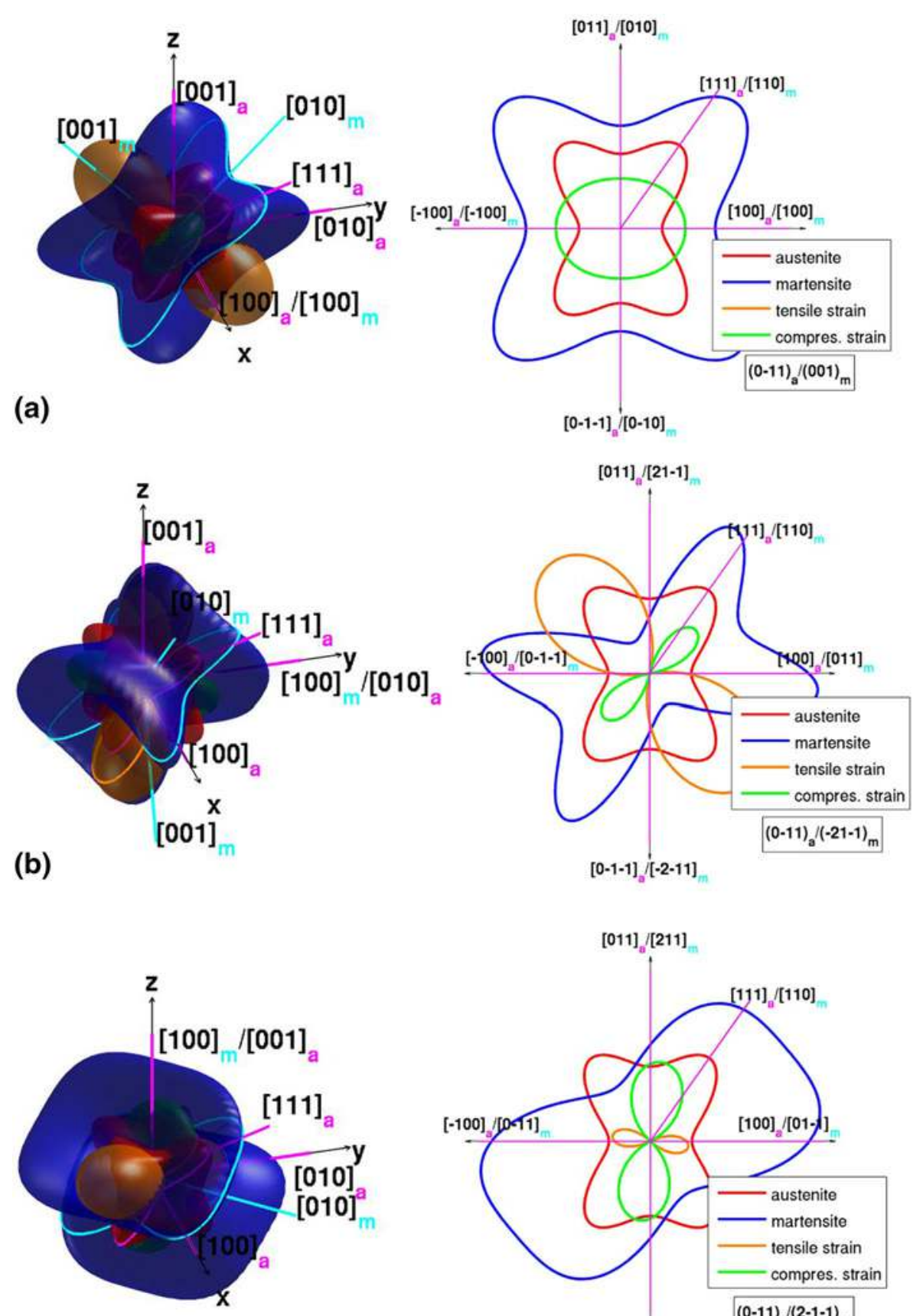

(c)

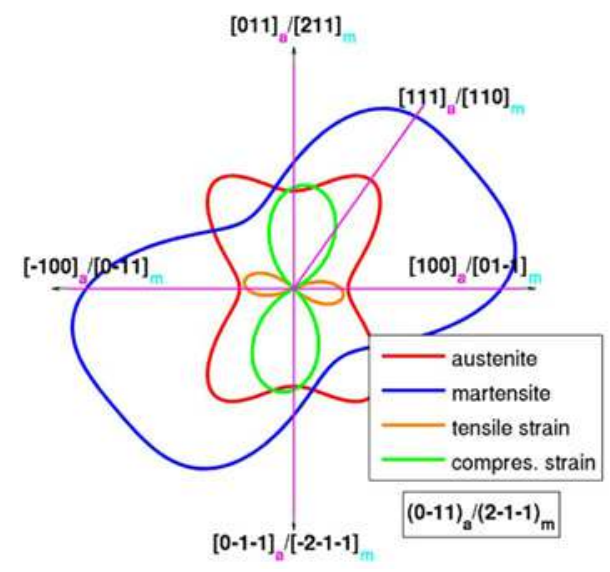

Fig. 8 Orientation dependence of Young's modulus (austenite in red and martensite in blue) and transformation strain (yellow in tension and green in compression) for austenite and martensite variants 1 (a), 5 (b), 9 (c) which appear preferentially in compression. The orientation dependences are shown in a form equal value surfaces in space and equal value contours in cross section along the (0-11) $a$ plane. Young's moduli surfaces are plot together with transformation strain surfaces to point out which directions are relevant for compression (Color figure online)

reaches out martenite surface along the $111_{a}$ directions for elastic constants from Ref 5, would be completely covered by the more isotropic martensite modulus surface in Fig. 11d (elastic constants from Ref 7). It is thus clear that the abovepresented analysis made for elastic constants from Ref 5 will be only partially valid for elastic constants from Ref 6 and not valid at all for the set from Ref 7).

Given the uncertainty in martensite elastic constants, we finally decide to perform a simple analysis of the sensitivity of the orientation dependence of martensite moduli to the used elastic constants. It was found that the unique anisotropy of the B19' martensite is sensitive mainly to the value of the elastic constant $\mathrm{C}_{55}$, which defines the depth of the minimum on the martensite Young's modulus surface which plays the critical role in tension. The effect of the variation of the elastic constant $\mathrm{C}_{55}$ on the shape of the martensite modulus surface is shown in Fig. 12 (for variant 3 in tension) and Fig. 13 (for variants 1, 5, 9 in compression). The lower is the $\mathrm{C}_{55}$, the deeper is the minimum. Low value of the $\mathrm{C}_{55}$ thus has large impact of the martensite modulus in tension but no impact on its value in 
compression. Inversely, this finding suggests that the $\mathrm{C}_{55}$ might be indeed as low as $21 \mathrm{GPa}$ (Ref 5) (set 1 in Table 3 used in the present analysis).

Finally, there is the possible softening of elastic constants of the B19' martensite upon heating. We know from the related work (Ref 2) that the dynamic $E^{\prime}$ martensite modulus in tension evaluated by DMA strongly decreases upon heating prior the reverse martensitic transformation reaching value as low as $20 \mathrm{GPa}$ at the As temperature. Given the above-revealed effect of $\mathrm{C}_{55}$, we propose that $\mathrm{C}_{55}$ might be one of the martensite elastic constants, which decreases (softens) upon heating the B19' martensite.

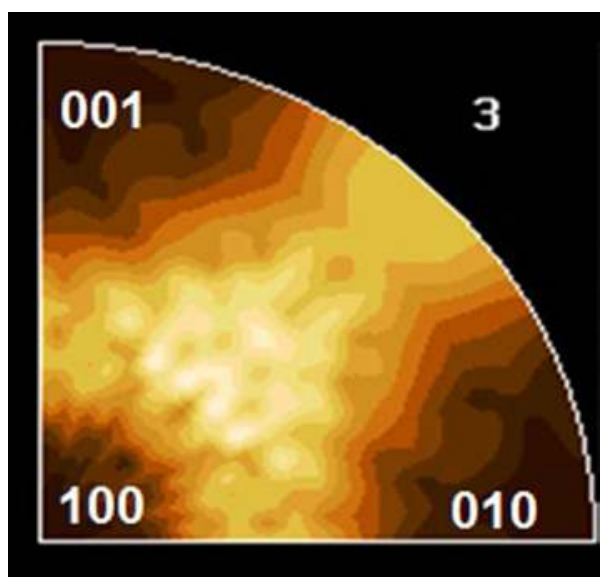

Fig. 9 Austenite texture of drawn NiTi wire measured by neutron diffraction (Ref 19) (inverse pole figure, bright color scales with occurrence of crystal orientations along the wire axis)

\section{Conclusions}

Young's moduli of superelastic NiTi wires in austenite and stress-induced martensite states were evaluated by three different experimental methods (tensile tests, in situ synchrotron x-ray diffraction, and dynamic mechanical analysis) and

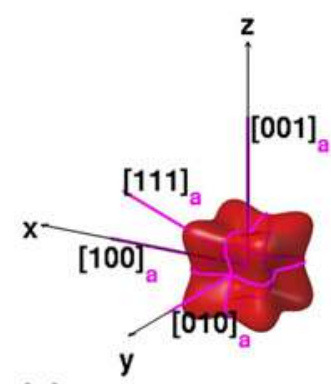

(a)

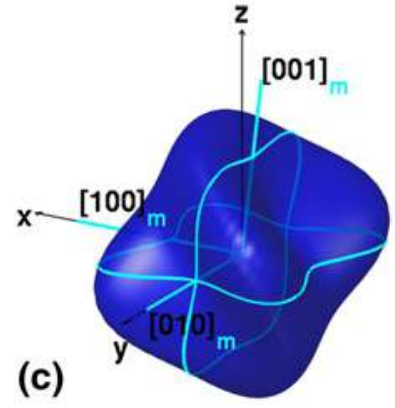

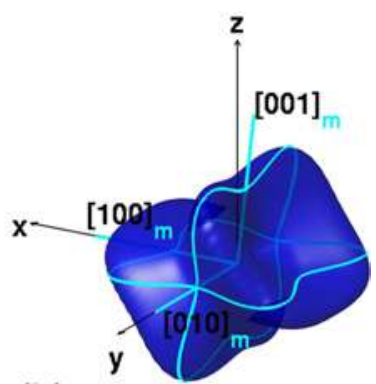

(b)

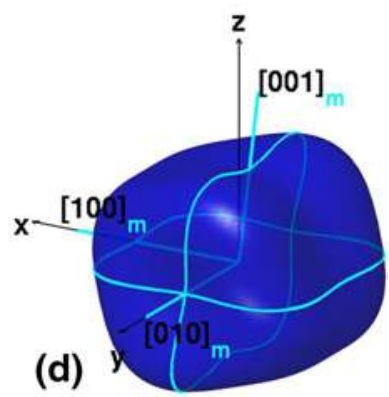

Fig. 11 Orientation dependence of Young's modulus for austenite (a) and martensite variant 3(b-d), which appears preferentially in tension for three different sets of elastic constants in Table 3. (b) Ref [5], (c) Ref [6], and (d) Ref [7]

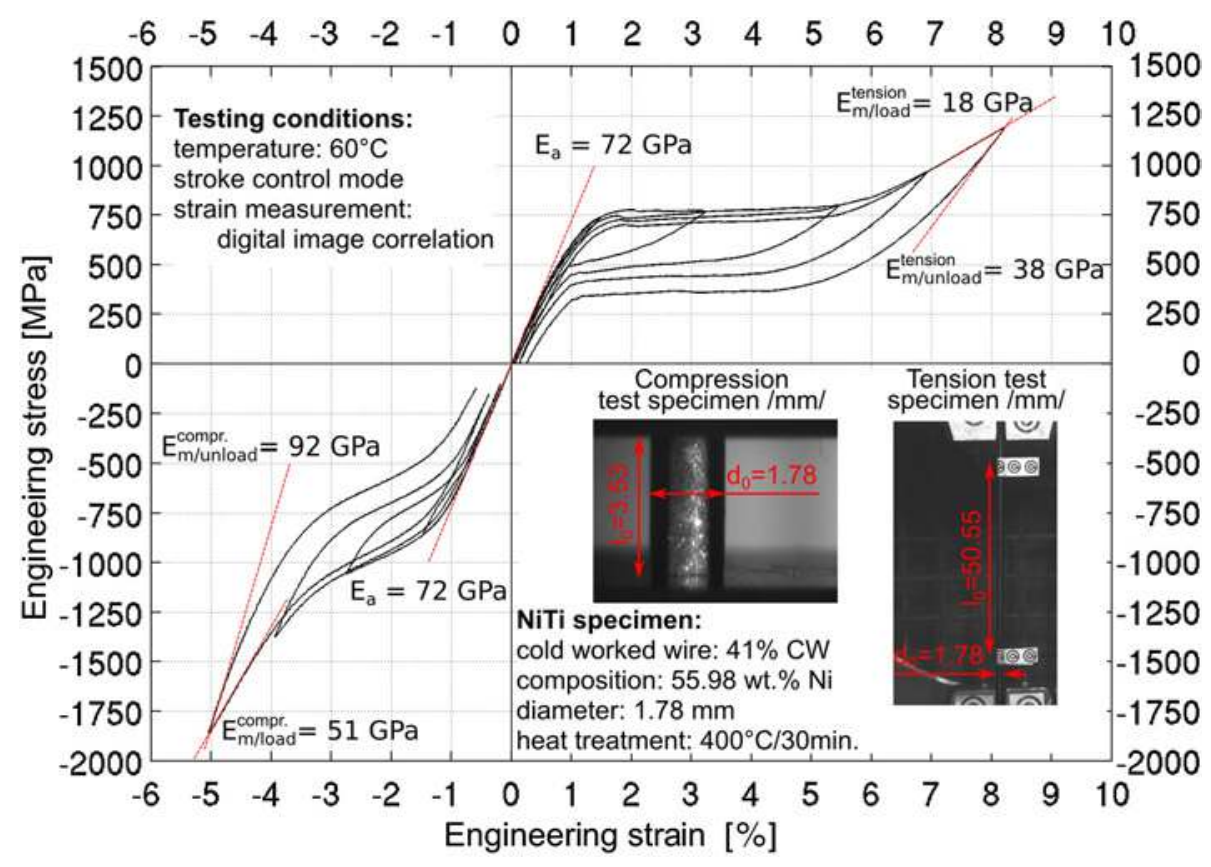

Fig. 10 Tension/compression loading of superelastic NiTi wire (NiTi $\# 1, d=1.78 \mathrm{~mm})$ at $T=60{ }^{\circ} \mathrm{C}$. Young's moduli of the wire in austenite and stress induced martensite were evaluated by conventional means from macroscopic mechanical response 


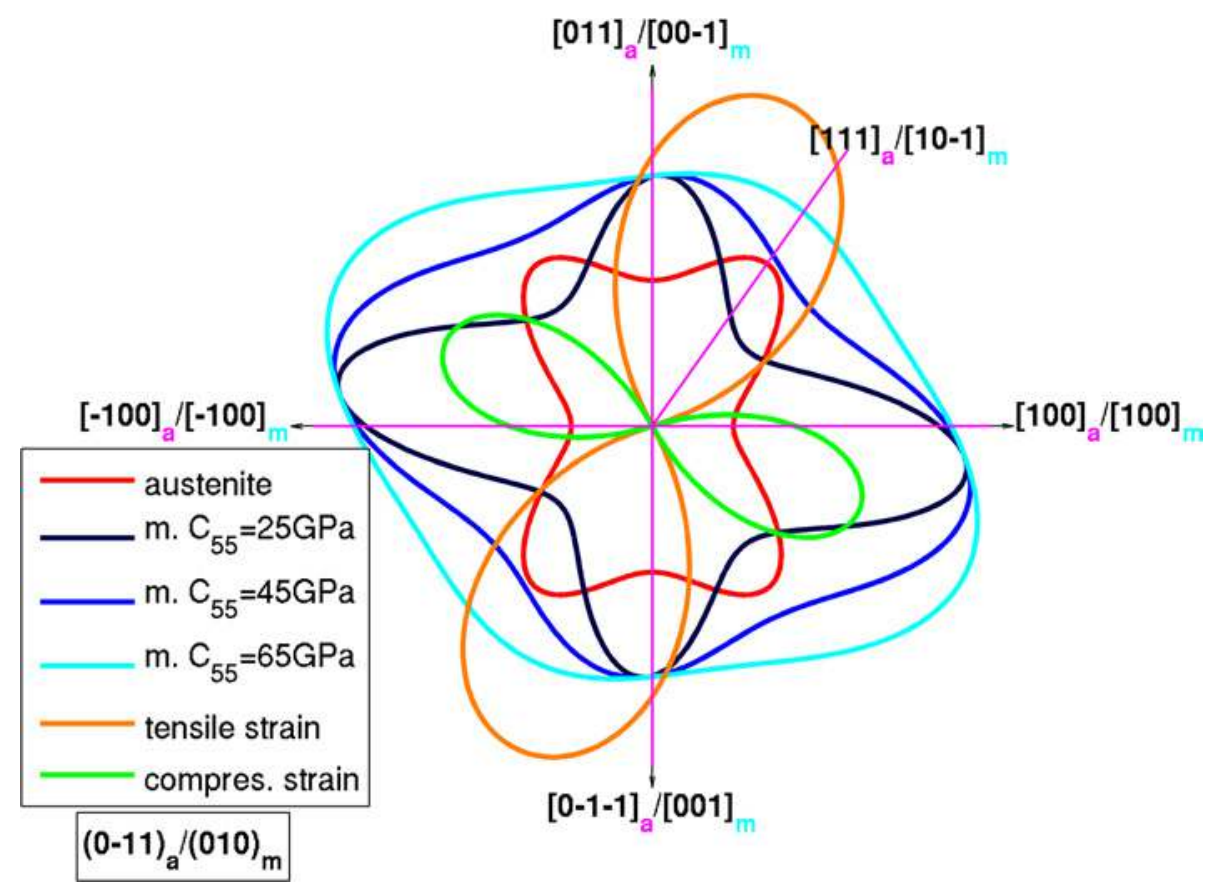

Fig. 12 Effect of martensite elastic constant C55 on Young's modulus surface of martensite in tension (martensite variant 3 preferred in tension, see Fig. 7 caption for details)

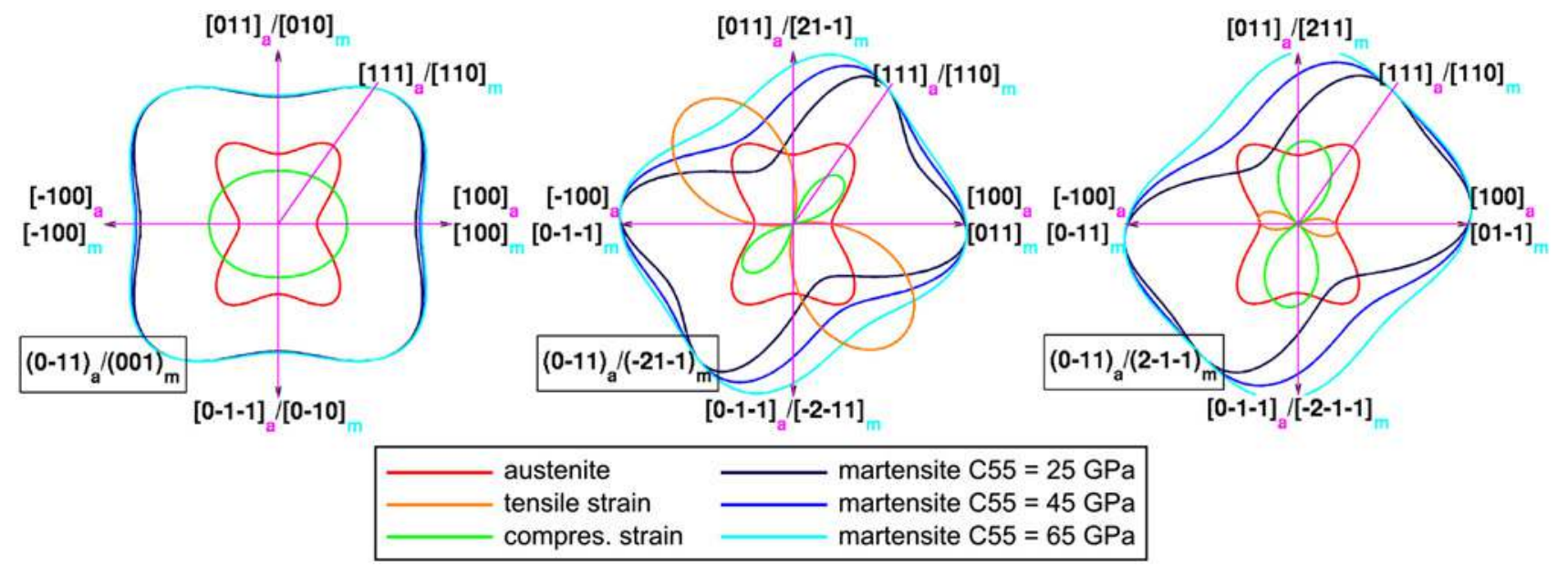

Fig. 13 Effect of martensite elastic constant C55 on Young's modulus of martensite in compression (martensite variants 1 (a), 5 (b), 9 (c) preferred in compression, see Fig. 8 caption for details)

estimated via theoretical calculation from elastic constants with the aim to resolve a long-lasting puzzle in the SMA field consisting in the apparently low value of the Young's modulus of the NiTi martensite.

Young's modulus of the B2 austenite in NiTi was found to be $E \sim 70 \mathrm{GPa}$ by all three experimental methods. If a smaller value is measured, then it is either due to the stress-induced B2$\mathrm{R}$ transformation and/or R-phase reorientation taking place during the supposedly elastic loading of austenite or due to internal intergranular stresses and residual martensite introduced into the wire microstructure. The activity of the R-phase related processes can be hardly recognized from the shape of the stress-strain curve but it can be easily understood from the results of in situ electric resistance or from the DMA experiments. Any value of the NiTi austenite modulus evaluated at temperatures far above the Ms which is lower than $70 \mathrm{GPa}$ is thus not real but due to the experimental issues.

On the contrary, the low value of martensite elastic modulus, which is generally ascribed in the literature to the martensitic transformation and/or twinning processes continuing beyond the transformation plateau, is claimed to be real in this work. Young's moduli of the stress-induced martensite as evaluated from the macroscopic stress-strain curves (25-50 GPa) and DMA $\left(E^{\prime}<50 \mathrm{GPa}\right)$ are indeed low. However, since the results of in situ X-ray diffraction experiments support much higher value $\left(D_{\mathrm{M}} \sim 120 \mathrm{GPa}\right)$, the experiments in this work did not provide clear answer. The issue was resolved through theoretical calculations of orientation-dependent Young's moduli using elastic constants theoretically predicted in the literature from first principles. The analysis has shown that the Young's 
modulus of the polycrystalline NiTi wire in the hard martensite state can be indeed as low as the $40 \mathrm{GPa}$ value commonly appearing in material property tables. It has been explained that this is due to the combination of the unique elastic anisotropies of the B2 austenite and B19' martensite, austenite drawing texture, and strong martensite texture due to B2-B19' transformation with martensite variant selection under tensile stress. This is, however, true only for tension, stress-free cooled or compressed NiTi bars yielding much higher martensite moduli due to their different variant selections and textures.

An additional analysis of the sensitivity of the orientation dependence of martensite moduli to the used elastic constants was carried out. It was found that the unique anisotropy of the B19' martensite responsible for the low martensite modulus in tension is sensitive to the value of the elastic constant $C_{55}$, which defines the depth of the minimum on the martensite Young's modulus surface. The lower is the $C_{55}$, the deeper is the minimum. Low value of the $\mathrm{C}_{55}$ thus has large impact of the martensite modulus in tension but no impact on its value in compression. It is suggested that $\mathrm{C}_{55}$ might be one of the martensite elastic constants which decreases (softens) upon heating.

\section{Acknowledgments}

This research has been supported from the Research Projects P107/12/0800, GA14-36566G, P108/12/P111 and GA14-15264S of the Grant Agency of the Czech Republic.

\section{References}

1. http://www.nitinol.com/nitinol-university/material-properties. Accessed 2 April 2014

2. T. Alonso, D. Favier, G. Chagnon, P. Sittner, and Y. Liu, Dynamic Mechanical Spectroscopy of Nanograined Thin NiTi Wires, Proc. SMST, Prague, Czech Republic, 2013

3. P. Sedlak, H. Seiner, M. Landa, V. Novák, P. Šittner, and L.I. Manosa, Elastic Constants of bcc Austenite and 2H Orthorhombic Martensite in CuAlNi Shape Memory Alloy, Acta Mater, 2005, 53, p 3643-3661

4. M. Landa, P. Sedlák, P. Šittner, H. Seiner, and V. Novák, Mater. Sci. Eng. A, 2007, 462, p 320-324

5. M.F.-X. Wagner and W. Windl, Lattice Stability, Elastic Constants and Macroscopic Moduli of NiTi Martensites from First Principles, Acta Mater., 2008, 56, p 6232-6245
6. P. Šesták, M. Černý, and J. Pokluda, Elastic Constants of Austenitic and Martensitic Phases of NiTi Shape Memory Alloy. In Recent Advances in Mechatronics 2008-2009, Springer, Berlin, 2009, p 1-6. ISBN 978-3-642-05021-3

7. N. Hatcher, O.Yu. Kontsevoi, and A.J. Freeman, Role of Elastic and Shear Stabilities in the Martensitic Transformation Path of NiTi, Phys. Rev. B, 2009, 80, p 144203

8. P. Šittner, M. Landa, P. Lukáš, and V. Novák, R-Phase Transformation Phenomena in Thermomechanically Loaded NiTi Polycrystals, Mech. Mater., 2006, 38, p 475-492

9. V. Novák, G.N. Dayananda, P. Šittner, F.M. Fernandes, and K.K. Mahesh, On the Electric Resistance Variation of NiTi and NiTiCu SMA Wires in Thermomechanical Cyclic Tests, Mater. Sci. Eng. A, 2008, 481-482, p 127-133

10. A.P. Stebner, D.W. Brown, and L.C. Brinson, Young's Modulus Evolution and Texture-Based Elastic-Inelastic Strain Partitioning During Large Uniaxial Deformations of Monoclinic Nickel-Titanium, Acta Mater., 2013, 61, p 1944-1956

11. R. Delville, B. Malard, J. Pilch, P. Sittner, and D. Schryvers, Microstructure Changes During Non-conventional Heat Treatment of Thin Ni-Ti Wires by Pulsed Electric Current Studied by Transmission Electron Microscopy, Acta Mater, 2010, 58, p 4503-4515

12. K. Otsuka and X. Ren, Physical Metallurgy of Ti-Ni-Based Shape Memory Alloys, Prog. Mater Sci., 2005, 50, p 511-678

13. K.F. Hane and T.W. Shield, Microstructure in the Cubic to Monoclinic Transition in Titanium-Nickel Shape Memory Alloys, Acta Mater, 1999, 47(9), p 2603-2617

14. H. Titrian, U. Aydin, M. Friák, D. Ma, D. Raabe, and J. Neugebauer, Self-Consistent Scale-Bridging Approach to Compute the Elasticity of Multi-Phase Polycrystalline Materials, Mater. Res. Soc. Symp. Proc., 2013, 1524

15. G. Sheng, S. Bhattacharyya, H. Zhang, K. Chang, S.L. Shang, S.N. Mathaudhu, Z.K. Liu, and L.Q. Chen, Effective Elastic Properties of Polycrystals Based on Phase-Field Description, Mater. Sci. Eng. A, 2012, 554, p 67-71

16. M. Kamaya, A Procedure for Estimating Young's Modulus of Textured Polycrystalline Materials, Int. J. Solids Struct., 2009, 46, p 2642-2649

17. X. Ren, N. Miura, J. Zhang, K. Otsuka, K. Tanaka, M. Koiwa, T. Suzuki, Yu.I. Chumlyakov, and M. Asai, A Comparative Study of Elastic Constants of Ti-Ni-Based Alloys Prior to Martensitic Transformation, Mater. Sci. Eng., 2001, A312, p 196-206

18. A.P. Stebner, D.W. Brown, and L.C. Brinson, Measurement of Elastic Constants of Monoclinic Nickel-Titanium and Validation of First Principles Calculations, Appl. Phys. Lett., 2013, 102, p 211908

19. P. Šittner, P. Lukáš, V. Novák, M.R. Daymond, and G.M. Swallowe, In-Situ Neutron Diffraction Studies of Martensitic Transformations in NiTi Polycrystals Under Tension and Compression Stress, Mater. Sci. Eng. A, 2004, 378(1-2), p 97-104

20. S. Rajagopalan, A1. Little, M.A.M. Bourke, and R. Vaidyanathan, Elastic Modulus of Shape-Memory NiTi from In Situ Neutron Diffraction During Macroscopic Loading, Instrumented Indentation, and Extensometry, Appl. Phys. Lett., 2005, 86(8), p 081901 